\title{
Analysis of deaths in a paediatric tertiary care centre 1996 - 1998
}

\author{
Pujitha Wickramasinghe $^{1}$, Sanath P Lamabadusuriya ${ }^{2}$, M V C de Silva ${ }^{3}$
}

Sri Lanka Journal of Child Health, 2000; 29: 88-92

(Key words: paediatric tertiary care centre, deaths)

\begin{abstract}
Objective To study in detail deaths of patients admitted to the Professorial Paediatric Unit at Lady Ridgeway Hospital (LRH), Colombo.
\end{abstract}

Design Retrospective study in 1996 and 1997 and prospective study in 1998.

Method Records of the deceased were analyzed in detail. Autopsies were performed whenever consent was obtained.

Results In 1996 there were 6302 admissions, 46 $(0.73 \%)$ deaths with $28(60.9 \%)$ being below the age of 1 year. Fourteen $(30.4 \%)$ deaths were due to infective causes and $09(19.5 \%)$ were due to congenital heart disease (CHD). Twenty six $(56.5 \%)$ died within 48 hours of admission. Male to female ratio was 1.1:1.

In 1997 the total number of admissions was 6102 with $49(0.8 \%)$ deaths and $28(57 \%)$ deaths occurred within 48 hours of admission. CHD accounted for $11(22.4 \%)$ deaths. In 1998 there were 5975 admissions and $68(1.14 \%)$ deaths. Eleven $(16.1 \%)$ were due to CHD and $30(44 \%)$ due to infections. $24(35 \%)$ of the deaths occurred in the months of April and May coinciding with the Influenza A epidemic. Male to female ratio was 1:1.03.

A similar pattern of deaths was seen in the three years except for April and May 1998. Annually about 20\% died of CHD. Respiratory tract infection was the commonest cause of death due to infections.

Conclusions Majority of deaths occurred under 1 year of age. The main cause of death in all age groups was infection. The second commonest cause of death was CHD. Majority of deaths occurred within 48 hours of admission suggesting that the condition of these patients was critical on admission.

${ }^{1}$ Lecturer in Paediatrics, ${ }^{2}$ Senior Professor of Paediatrics, ${ }^{3}$ Senior Lecturer in Pathology, Faculty of Medicine, University of Colombo.

\section{Introduction}

Mortality data of a tertiary care centre will not be a reflection of national statistics but it will indicate the pattern of disease and the impact of chronic life-threatening illnesses on children.

\section{Methods}

All the records of patients who died during the 3 year period were analyzed in detail. Autopsies were carried out whenever consent was obtained and these autopsies were performed by a pathologist when available.

\section{Results}

Annual number of admissions to the unit and the respective number of deaths are shown in Table 1.

Table 1

Number of admissions and deaths

\begin{tabular}{|c|c|c|}
\hline Year & $\begin{array}{c}\text { Total } \\
\text { admissions }\end{array}$ & Deaths \\
\hline 1996 & 6302 & $46(0.73 \%)$ \\
\hline 1997 & 6102 & $49(0.80 \%)$ \\
\hline 1998 & 5975 & $68(1.14 \%)$ \\
\hline
\end{tabular}

Mean death rate was $0.89 \%$. The sex distribution of the deceased is almost equal (Figure 1).

Figure 2 shows the comparison of the distribution of deaths throughout the year for 1996, 1997 and 1998. Majority of deaths, $56.5 \%, 57.1 \%$ and $57.3 \%$ for ' 96, ' 97 and '98 respectively had occurred within 48 hours after admission (Table 2).

Table 2

Time of death after admission

\begin{tabular}{|c|c|c|}
\hline Year & $\begin{array}{c}<48 \text { hrs after } \\
\text { admission }\end{array}$ & $\begin{array}{c}>48 \text { hrs after } \\
\text { admission }\end{array}$ \\
\hline 1996 & $26(56.5 \%)$ & $20(43.5 \%)$ \\
\hline 1997 & $28(57.0 \%)$ & $21(43.0 \%)$ \\
\hline 1998 & $39(57.3 \%)$ & $29(42.7 \%)$ \\
\hline
\end{tabular}




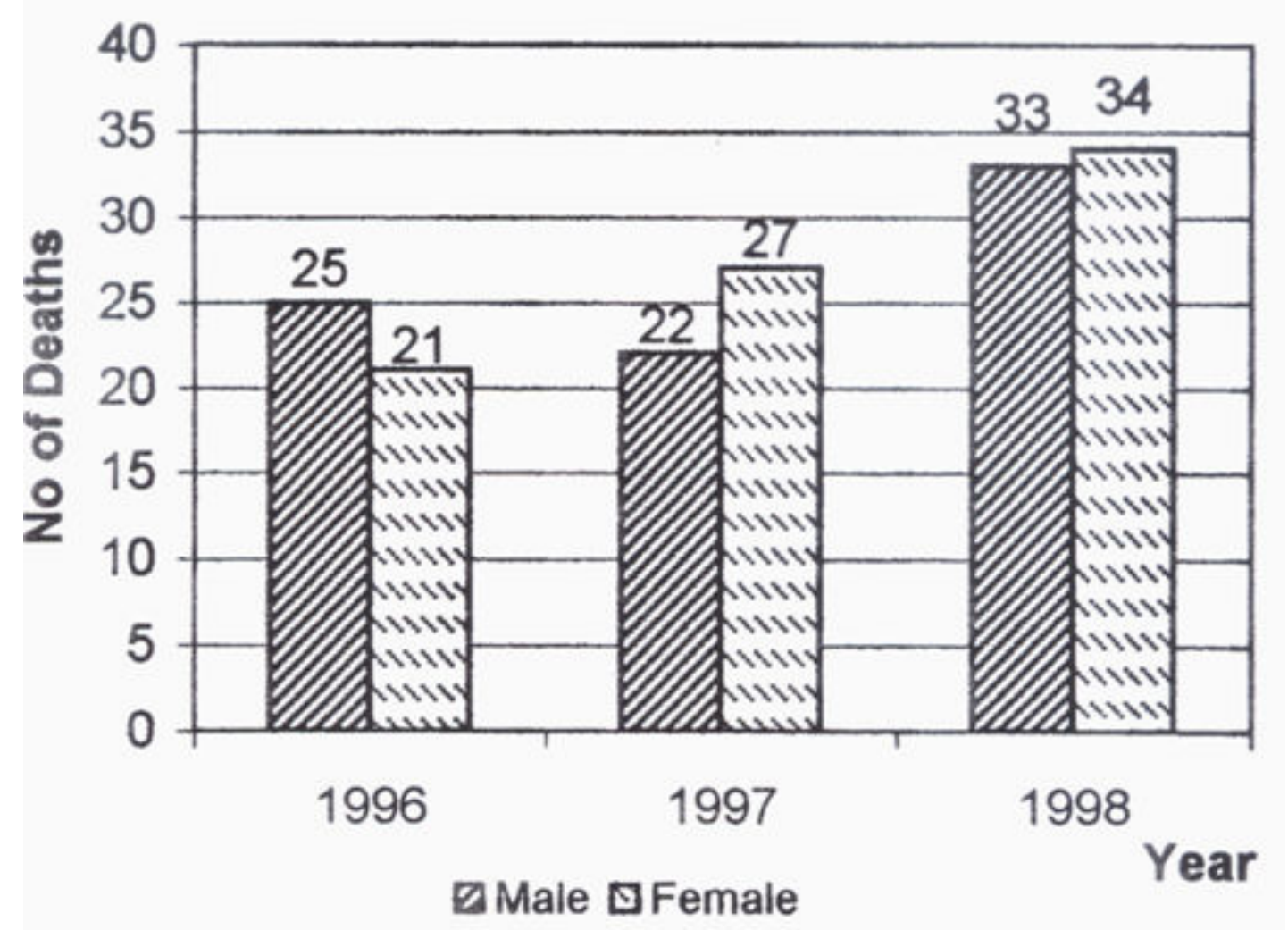

Figure 1 Sex distribution

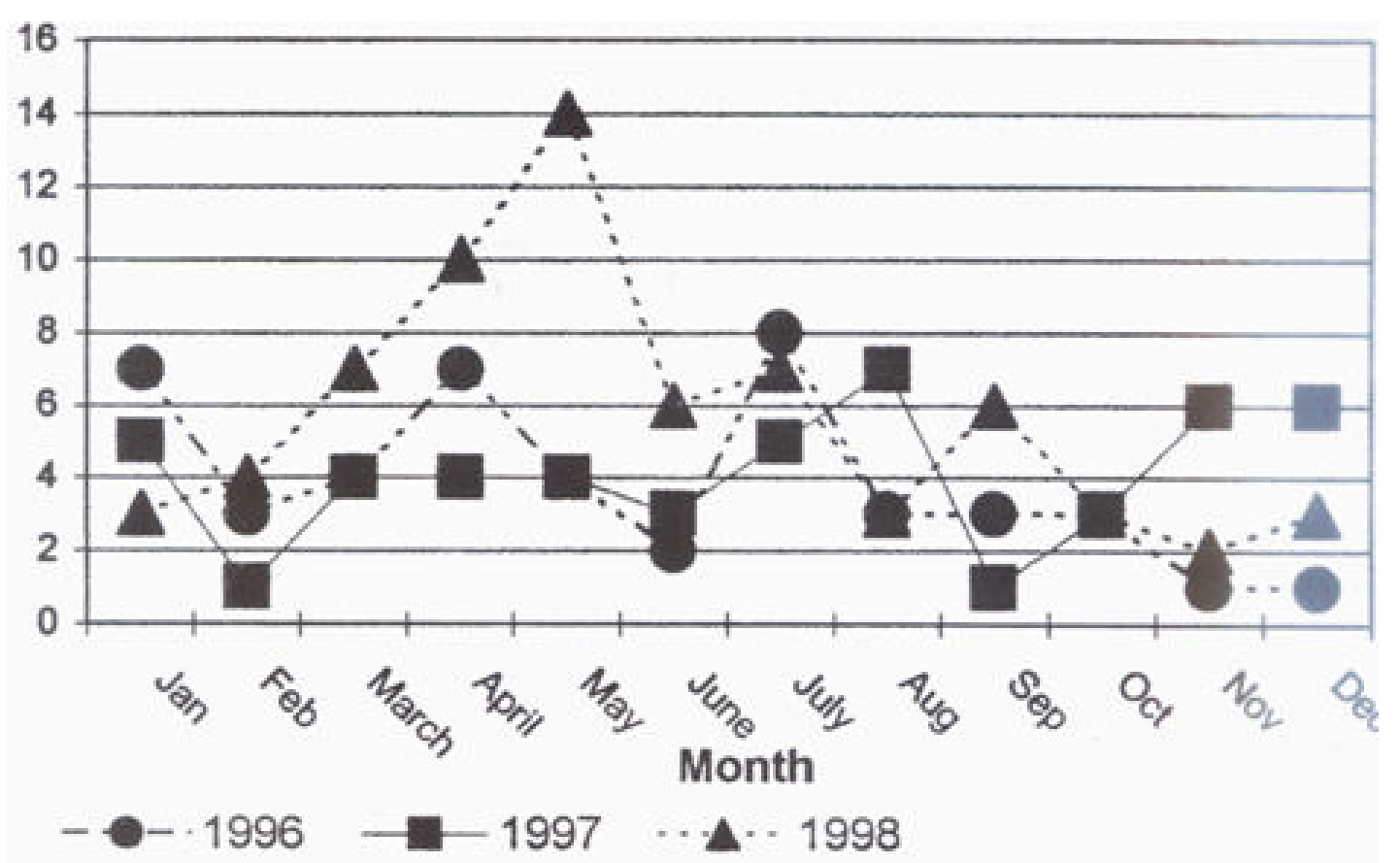

Figure 2 Sex distribution of deaths throughout the years

Table 3 shows the age distribution of the deceased children and the majority were infants in all 3 years. Infection was the main cause of death. Pneumonia was the single commonest infective cause of death in each of the three years. The second commonest cause of death had been congenital heart disease accounting for $16.2 \%$ to $19.5 \%$ of the total deaths (Table 4). 
Table 3

Age distribution

\begin{tabular}{|l|c|c|c|}
\hline \multicolumn{1}{|c|}{ Age } & 1996 & 1997 & 1998 \\
\hline$<1$ month & $08(17.3 \%)$ & $08(16.3 \%)$ & $08(11.7 \%)$ \\
\hline $1-12$ months & $20(43.4 \%)$ & $19(38.7 \%)$ & $26(38.2 \%)$ \\
\hline $13-59$ months & $07(15.2 \%)$ & $10(20.5 \%)$ & $19(28.0 \%)$ \\
\hline $5-10$ years & $10(21.9 \%)$ & $10(20.5 \%)$ & $12(17.6 \%)$ \\
\hline$>10$ years & $01(02.2 \%$ & $02(04.0 \%)$ & $03(04.5 \%)$ \\
\hline
\end{tabular}

Table 4

Cause of death

Cause

Infections

Septicaemia
Pneumonia
Encephalitis
Others

Congenital Heart Disease

Reye/Reye like illness

Renal Failure

Others

Total
1996

$14(30.5 \%)$

$\begin{array}{ccc}4 & & \\ 5 & & \\ 1 & & \\ 4 & & \\ & & \\ & 9(19.5 \%) \\ & 8(17.3 \%) \\ & 1(2.2 \%) \\ & 14(30.5 \%) \\ & 46(100.0 \%)\end{array}$

1997

$19(38.7 \%)$

\section{5}

8

3

2
In 1996 there had been one death due to dengue haemorrhagic fever. In 1997 there had been one case of rabies and another death due to accidental poisoning with paraquat. In 1998 there were 15 deaths due to pneumonia. Ten had occurred in the months of April and May coinciding with the influenza A epidemic. Seven out of the 8 deaths due to a Reye like illness also occurred in the same period. There was one case

$\begin{array}{crc} & 10 & \\ & 20 & \\ & 1 & \\ & 6 & \\ & & \\ & & 11(16.2 \%) \\ 11(22.4 \%) & & 8(11.7 \%) \\ 4(8.1 \%) & & 1(1.5 \%) \\ 3(6.3 \%) & & 11(16.2 \%) \\ 12(24.5 \%) & & 68(100.0 \%) \\ 49(100.0 \%) & & \end{array}$

each of acute gastroenteritis and systemic lupus erythematosus. There was one death due to chronic rheumatic heart disease. There were 3 deaths due to Wilson disease and 2 were siblings.

Table 5 shows the analysis of cause of deaths according to the age group.

Table 5

Cause of death of each age group

\begin{tabular}{|c|c|c|c|c|c|c|c|c|c|c|c|c|}
\hline & \multicolumn{4}{|c|}{1996} & \multicolumn{4}{|c|}{1997} & \multicolumn{4}{|c|}{1998} \\
\hline & $<1 \mathrm{~m}$ & $1-12 \mathrm{~m}$ & $1-4 \mathrm{yr}$ & $>5 y r$ & $<1 \mathrm{~m}$ & $1-2 m$ & $1-4 \mathrm{yr}$ & $>5 y r$ & $<1 \mathrm{~m}$ & $1-12 \mathrm{~m}$ & $1-4 \mathrm{yr}$ & $>5 y$ \\
\hline Infections & 5 & 5 & 3 & 1 & 4 & 7 & 4 & 4 & 3 & 17 & 11 & 6 \\
\hline $\mathrm{CHD}$ & 1 & 7 & 1 & $\cdot$ & 3 & 5 & 2 & 1 & 3 & 5 & 2 & 1 \\
\hline Reye/Reye like illness & $\cdot$ & 2 & 2 & 4 & - & 1 & 1 & 2 & $\cdot$ & 1 & - & - \\
\hline Renal Failure & $\cdot$ & - & - & 1 & 1 & 2 & - & - & - & 1 & - & - \\
\hline Others & 2 & 6 & 1 & 5 & - & 4 & 3 & 5 & 2 & - & 2 & - \\
\hline Total & 8 & 20 & 7 & 11 & 8 & 19 & 10 & 12 & 8 & 26 & 19 & 15 \\
\hline
\end{tabular}

In 1998 fourteen $(20.8 \%)$ autopsies were performed and the majority was by a pathologist.

\section{Discussion}

Annually the death rate had been just under $1 \%$. In 1998 it had been $1.14 \%$ which was due to the increase in the number of deaths related to the Influenza A virus epidemic. There had been 24 deaths in April and May 1998 and of these 17 had been due to Reye like illness or pneumonia.
Majority of deaths have occurred within $48 \mathrm{hrs}$ of admission which suggests that the majority of patients were in a critical state at the time of admission. The distribution of deaths throughout the year had been taking a similar pattern except for April and May 1998, which had a high number of deaths, compared to the same period of the past 2 years, due to Influenza A virus epidemic. 
The highest death rate was seen in infancy, probably because it is a more vulnerable period to acquire infections; complications of serious congenital defects such as congenital heart disease are likely to manifest during this period.

Irrespective of the age group the main cause of death is infection. Respiratory tract infections were responsible for the majority of deaths reflecting the difficulty in its control. Septicaemia had been the major killer in the neonates. During the 3 years there had been only 1 death due to a diarrhoeal illness, highlighting the effectiveness in managing diarrhoeal illnesses; this death was in a child with spastic cerebral palsy with feeding difficulties. There was only one death due to dengue haemorrhagic fever for the three year period and the low mortality is probably due to the detection and management of such cases early in the course of the illness due to high vigilance. There were no deaths due to any of the illnesses prevented by the vaccines in the extended programme of immunization (EPI). Congenital heart disease had been the second commonest cause of death and it has been so in the professorial paediatric unit at LRH from 1992 to 1998 accounting for $16 \%$ to $30.8 \%$ of the total deaths ${ }^{1}$.

\section{Conclusions}

Majority of deaths were under one year and the main cause of death irrespective of the age group was infections of which respiratory tract infection (RTI) was the commonest type. RTI is the commonest cause of death in children globally, after deaths due to acute gastroenteritis were drastically reduced with the availability of oral hydration therapy ${ }^{2,3}$. At LRH, the admissions of children suffering from acute gastroenteritis have been reduced dramatically with the establishment of a diarrhoea therapy unit in the outpatient department.

Second commonest cause of death was congenital heart disease of which an appreciable number would have benefited from corrective surgery. Therefore improvement in the surgical facilities will substantially reduce the number of deaths due to congenital heart disease and it would help to reduce the infant mortality rate further. As majority of deaths occurred within 48 hours of admission, perhaps these could be reduced by increasing the awareness among the public when they should seek medical advice; early referral of such patients from the primary and secondary care levels would undoubtedly be helpful. The other major factors that have contributed to a reasonably low mortality rate of $<1 \%$ are the availability of an intensive care unit and establishment of emergency rooms in the medical units. The quality of care could be enhanced further if the out patient department at LRH is staffed with medical officers with paediatric experience such as those with a Diploma in Child Health (DCH).

In developed countries, morbidity and mortality due to Haemophilus influenzae type b (Hib) infection have been drastically reduced by the introduction of $\mathrm{Hib}$ vaccine into the national immunization schedules ${ }^{4}$. In a study carried out in the Gambia, the overall incidence of pneumonia was also effectively reduced by the use of Hib vaccine ${ }^{5}$. Although the Hib vaccine is available in the private sector in Sri Lanka, its cost precludes its inclusion in the national EPI schedule at present. However, with assistance from donor agencies such as GAVI (Global Alliance for Vaccines and Immunizations) or the Bill and Melinda Gates Foundation, Sri Lanka should attempt to have the Hib vaccine in its EPI schedule. If and when that goal is achieved the deaths due to Haemophilus influenza type $\mathrm{b}$ infection (meningitis, septicaemia, pneumonia etc) would be a thing of the past.

\section{Acknowledgements}

The authors wish to express their sincere thanks to the parents who gave their consent for autopsies. They are also thankful to the registrars and house officers of the professorial paediatric unit who helped in the study.

\section{References}

1. Lamabadusuriya $\mathrm{S}$ P. High mortality from congenital heart disease, a letter to editor. Ceylon Medical Journal 1999; 44: 99.

2. World Health Organization. Infectious diseases according to mode of transmission. In: The World Health Report 1996, Geneva; WHO: 2358 .

3. Cleason M, Merson M H. Global progress in the control of diarrhoeal disease. Paediatric Infectious Disease Journal 1990; 9:345-55.

4. Steinholf M C, Haemophilus influenzae type b infections are preventable everywhere commentary. Lancet 1997; 349:1186-7.

5. Mulholland $\mathrm{K}$, Hilton $\mathrm{S}$, Adegbola $\mathrm{R}$ et. al. Randomized trial of Haemophilus influenzae type $\mathrm{b}$ tetanus protein conjugate for prevention of pneumonia and meningitis in Gambian infants. Lancet 1997; 349:1191-7. 